\title{
Extended Endoscopic Endonasal Approach for Craniopharyngioma Removal
}

Mahmoud Messerer ${ }^{1,2}$ Rodolfo Maduri ${ }^{1}$ Roy Thomas Daniel ${ }^{1,2}$

\begin{abstract}
Address for correspondence Rodolfo Maduri, MD, Department of Clinical Neurosciences, Service of Neurosurgery, Centre Hospitalier Universitaire Vaudois, 41 Rue du Bugnon Lausanne, Lausanne 1011, Switzerland (e-mail: rodolfo.maduri@gmail.com).
\end{abstract}

J Neurol Surg B 2018;79(suppl S2):S199-S200.

\begin{abstract}
Keywords

- craniopharyngioma

- extended endonasal approach

- endoscopy

- parasellar lesions

- transsphenoidal surgery

Objective Endoscopic transsphenoidal extended endoscopic approach (EEA) represents a valid alternative to microsurgery for craniopharyngiomas removal, especially for retrochiasmatic lesions without large parasellar extension. The present video illustrates the salient surgical steps of the EEA for craniopahryngioma removal.

Patient A 52-year-old man presented with a bitemporal hemianopia and a bilateral decreased visual acuity. MRI showed a Kassam type III cystic craniopharyngioma with a solid component (- Fig. 1, panels A and B).

Surgical Procedure The head is rotated 10 degrees toward the surgeons. The nasal step is started through the left nostril with a middle turbinectomy. A nasoseptal flap is harvested and positioned in the left choana. The binostril approach allows a large sphenoidotomy to expose the key anatomic landmarks. The craniotomy boundaries are the planum sphenoidale superiorly, the median opticocarotid recesses, the internal carotid artery laterally and the clival recess inferiorly. After dural opening and superior intercavernous sinus coagulation, the tumor is entirely removed ( $\mathbf{- F i g . ~ 2 , ~ p a n e l s ~ A ~ a n d ~ B ) . ~ S k u l l ~ b a s e ~ r e c o n s t r u c t i o n ~ i s ~}$ ensured by fascia lata grafting and nasoseptal flap positioning.

Results Postoperative MRI showed the complete tumor resection (-Fig. 1, panels C and $\mathrm{D}$ ). At 3 months postoperatively, the bitemporal hemianopia regressed and the visual acuity improved. A novel left homonymous hemianopia developed secondary to optic tract manipulation.

Conclusions The extended EEA is a valid surgical approach for craniopharyngioma resection. A comprehensive knowledge of the sellar and parasellar anatomy is mandatory for safe tumor removal with decreased morbidity and satisfactory oncologic results. The link to the video can be found at: https://youtu.be/NrCPPnVK2qA.
\end{abstract}

Conflict of Interest

None.

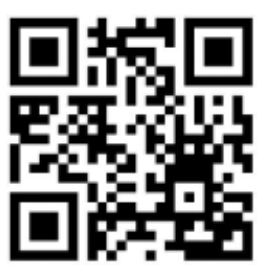

received

October 5, 2017

accepted

December 7, 2017

published online

January 16, 2018

www.thieme.com/skullbasevideos

www.thieme.com/jnlsbvideos

DOI https://doi.org/

10.1055/s-0038-1623527.

ISSN 2193-6331.
๑) 2018 Georg Thieme Verlag KG
Stuttgart · New York

License terms

(c) $(1) \$$ 


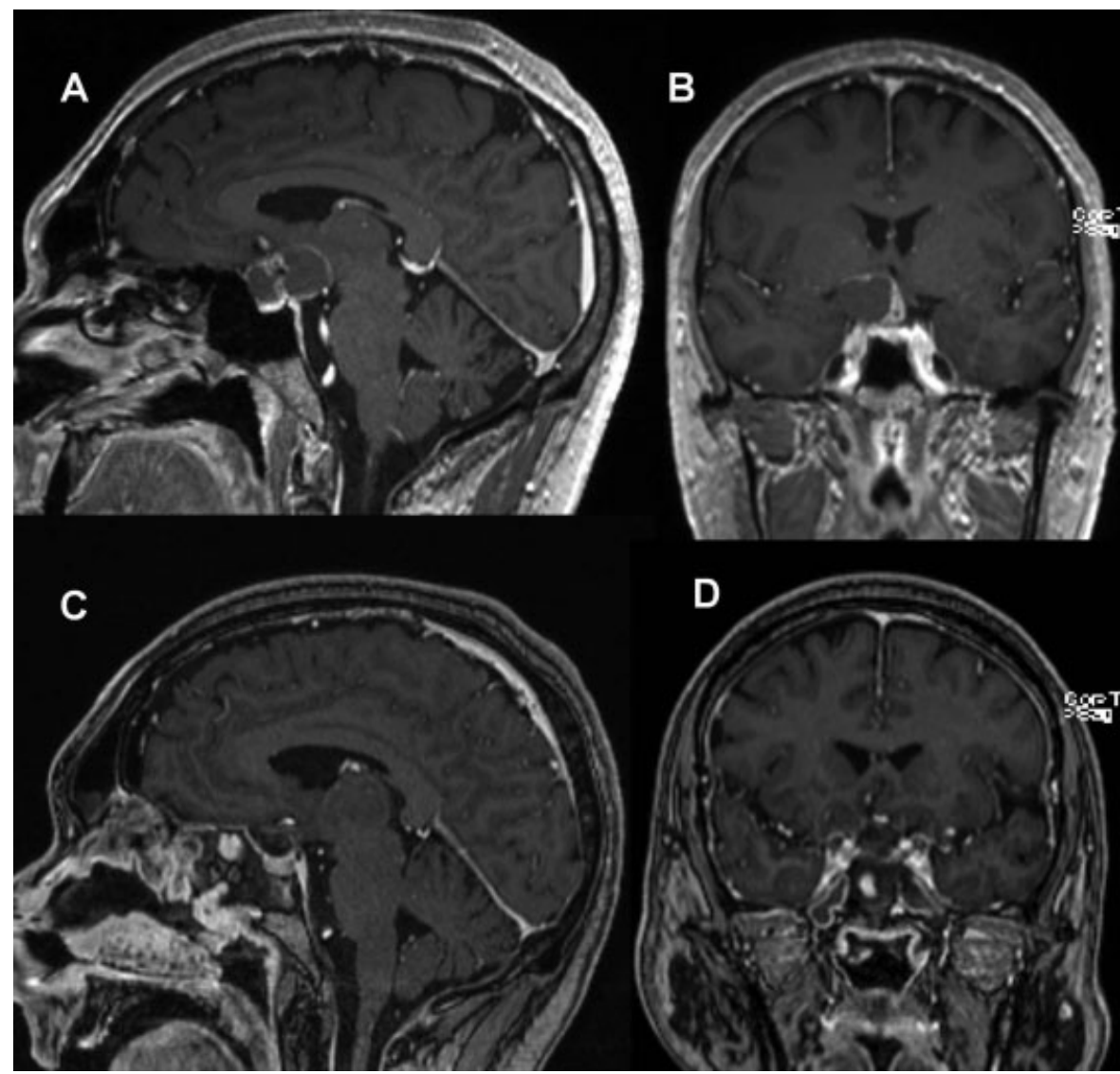

Fig. 1 Preoperative sagittal (A) and axial (B) MRI showing a Kassam III cystic craniopharyngioma with a solid component, exerting mass effect on the optic chiasm. Postoperative sagittal (C) and axial (B) MRI showing complete resection of the craiopharyngioma.

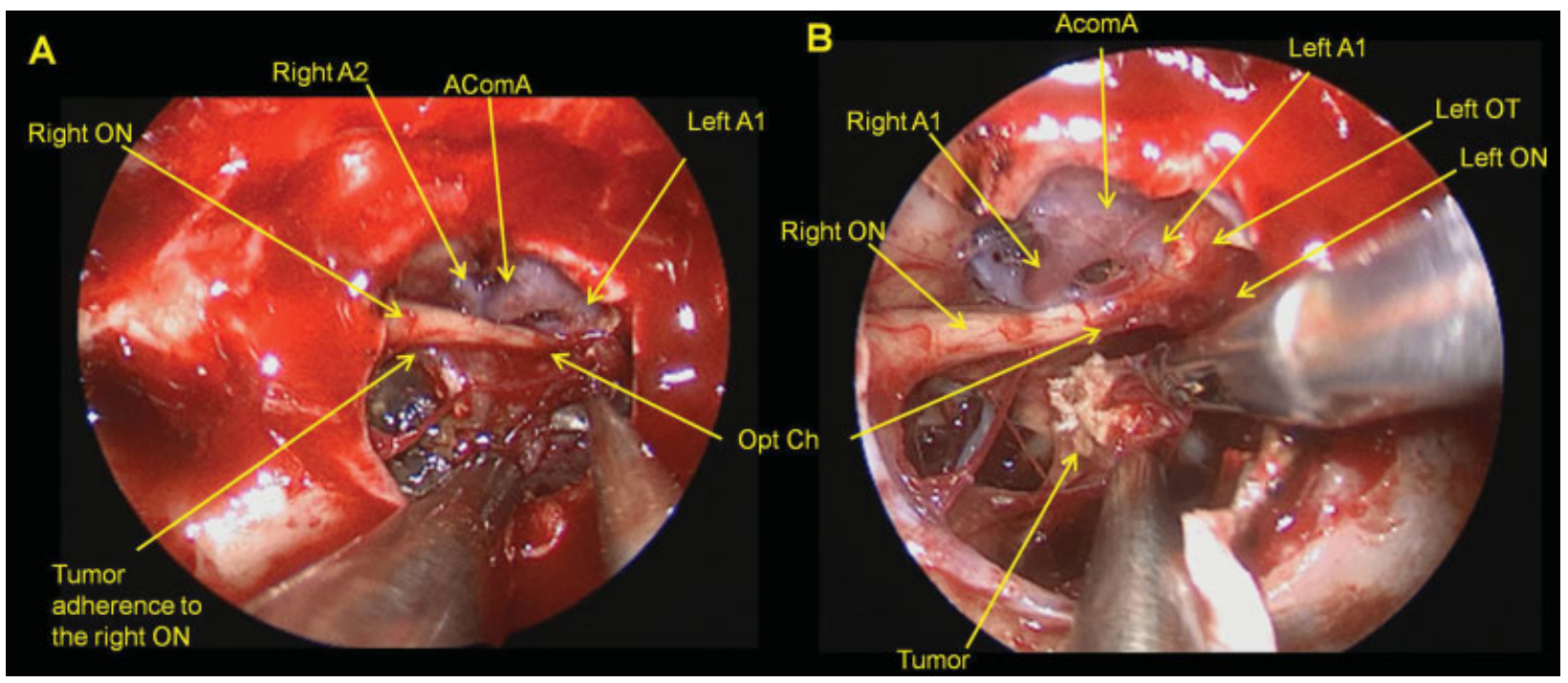

Fig. 2 Operative pictures of the intradural phase. (A) shows tumor dissection from its adhesions to the right ON. (B) shows the resection of the residual craniopharyngioma after careful dissection from the right ON. The EEA allows wide exposure of the anterior communicating vascular complex, both optic nerves, the optic chiasm and tracts, the pituitary stalk. Abbreviations. AComA, anterior communicating artery; OptCh, optic chiasm; ON: optic nerve, OT, optic tract. 